\title{
A Quantitative Method for Determining Soil Populations of Streptomyces and Differentiating Potential Potato Scab-Inducing Strains
}

Kenneth L. Conn and Edlira Leci, Agriculture and Agri-Food Canada (AAFC), Pest Management Research Center (PMRC), 1391 Sandford St., London, Ontario, Canada N5V 4T3; Giora Kritzman, Department of Plant Pathology, ARO, The Volcani Center, Bet Dagan 50250 Israel; and George Lazarovits, AAFC, PMRC, 1391 Sandford St., London, Ontario, Canada N5V 4T3

\begin{abstract}
Conn, K. L., Leci, E., Kritzman, G., and Lazarovits, G. 1998. A quantitative method for determining soil populations of Streptomyces and differentiating potential potato scab-inducing strains. Plant Dis. 82:631-638.

A procedure is described for estimating Streptomyces populations in soil. Soils are air-dried, 10$\mathrm{g}$ quantities are shaken in plastic bags containing $0.1 \%$ water agar and homogenized with a Stomacher homogenizer, serial dilutions are plated on a semi-selective culture (STR) medium and incubated for 2 weeks at $22^{\circ} \mathrm{C}$, and the Streptomyces colonies are enumerated. Use of STR medium reduced the bacterial and fungal colonies recovered from soil to levels below that of the Streptomyces spp. while not affecting the number of Streptomyces colonies compared with those enumerated on yeast malt extract medium. A procedure for screening large numbers of Streptomyces strains for thaxtomin production, a phytotoxin recognized as a virulence marker in $S$. scabies, is also described. Strains are grown on oatmeal medium, and the thaxtomin is extracted from the medium by facilitated diffusion and detected by miniature thin layer chromatography. S. scabies and S. acidiscabies strains (approximately 130 from Ontario and 70 from other locations in North America) that produced thaxtomin did not form aerial mycelia or sporulate on STR medium within 2 weeks at $22^{\circ} \mathrm{C}$. Ontario S. scabies strains that produced thaxtomin A also produced melanin on STR medium. All S. scabies strains from scab lesions that produced thaxtomin A had this colony morphology, whereas only 4 to $9 \%$ of strains from soil with this colony morphology produced thaxtomin A. Using these procedures, we determined that the population of thaxtomin-producing $S$. scabies in soil from a potato field in Ontario with a history of potato scab was about $20,000 \mathrm{CFU} / \mathrm{g}$ soil.
\end{abstract}

Additional keywords: common scab, deep pitted scab, soilborne pathogen

Potato scab is an economically important disease in North America and Europe $(20,26)$. This disease is caused by bacteria belonging to several Streptomyces spp. $(4,6,7,8,9,26)$, but $S$. scabies is the predominant causal agent (21). S. acidiscabies is the predominant causal agent in soils below pH 5 (26). Depending on the Streptomyces strain and the environment, shallow, raised, or deep-pitted lesions develop $(9,11,26)$. Pathogenic Streptomyces strains produce phytotoxins named thaxtomins, which are thought to be involved in pathogenicity $(3,17,22,23,25)$. Thaxtomin $\mathrm{A}$ is the most abundant phytotoxin produced by $S$. scabies and $S$. acidiscabies, along with about nine minor thaxtomins (15). Thaxtomin $\mathrm{C}$ is the most abundant phytotoxin

Corresponding author: G. Lazarovits

E-mail: lazarovitsg@em.agr.ca

Accepted for publication 14 March 1998.

Publication no. D-1998-0420-04R

This article is in the public domain and not copyrightable. It may be freely reprinted with customary crediting of the source. The American Phytopathological Society, 1998. produced by $S$. ipomoeae, the cause of soil rot of sweet potato (16).

In Ontario, the incidence of scab is erratic and uneven, even within a field. Tubers from infested sites are often unmarketable, particularly if deep-pitted lesions occur. For some growers, this disease has become a limiting factor in production. Pathogenic Streptomyces spp. pose a longterm threat to potato production because they can survive in soil or on plant residues for over a decade (18). Control of this pathogen has not been seriously attempted in Ontario. Development of disease control methods using biological and chemical materials or soil amendments is constrained by the lack of a rapid and quantitative technique for measuring populations of pathogenic Streptomyces spp. in soil. Most media for selective isolation of Streptomyces spp. from soil or scab lesions use antibiotics such as cycloheximide, nystatin, polymyxin $\mathrm{B}$, and penicillin $G$ to reduce the growth of unwanted bacteria and fungi $(7,8,13,14,27)$. The selection of these antibiotics and the concentrations used was derived from studies where actinomycetes were isolated from a pine forest soil $(2,31)$. These researchers stressed that some actinomycetes were inhibited by these antibiotics and the importance of testing the effect of antibiotics against target organisms before any new ecological investigation began. However, such tests have never been carried out for isolation of Streptomyces bacteria from soil from a potato field. When we tested media containing these antibiotics for isolation of S. scabies from soil from potato fields that had been amended with organic amendments, we encountered two problems. One was that these antibiotics did not provide sufficient selection for Streptomyces spp., particularly from soils where organic amendments had dramatically increased bacterial numbers. High populations of nonfilamentous bacteria obscured $S$. scabies colonies on dilution plates. In addition, $S$. scabies strains that we isolated from scab lesions did not grow on media containing these antibiotics. Thus, we developed a medium that is selective for $S$. scabies strains found in soils from Ontario potato fields by modifying the type and quantities of antibiotics used. We also tested the effect of various concentrations of $\mathrm{NaCl}$ on selectivity of the medium.

Enumeration of $S$. scabies in infested soil does not provide an estimation of scab potential, however, since pathogenic $S$. scabies strains comprise only a small proportion of the total population. Keinath and Loria (13) isolated Streptomyces spp. from soil and identified S. scabies based on colony and spore morphology. When these strains were infested into soil in which potato plants were grown for 2 months in the greenhouse, only $3.3 \%$ of the $S$. scabies strains were pathogenic. This method is too time-consuming and labor intensive to be useful for evaluating populations of $S$. scabies from potato soils. In addition, the characteristic of pathogenicity among these strains can be inaccurately assessed using greenhouse assays. Production of melanin has been used as a diagnostic characteristic of S. scabies (14), but it does not differentiate between pathogenic and nonpathogenic strains. Attempts have been made to find genetic markers that can be used to identify pathogenic $S$. scabies strains. Analyses of 16S rRNA sequences (29), fatty acid methyl ester profiles (28), restriction fragment length polymorphisms (4), and DNA-DNA hybridization $(10,30)$ have been carried out. The general conclusion from these studies is that pathogenic 
S. scabies strains comprise a genetically diverse population. If this conclusion is correct, it would exclude the use of these techniques for quantifying pathogenic $S$. scabies in soil. We decided to focus on thaxtomin production as a marker for pathogenicity since in North America this appears to be an excellent indicator of pathogenicity of $S$. scabies on potatoes $(17,22,23,25)$. To help screen $S$. scabies and $S$. acidiscabies strains for thaxtomin production, we took advantage of the fact that they can be induced to produce thaxtomins in oatmeal medium $(1,25)$.

The objectives of this research were to (i) develop a semi-selective medium to isolate Streptomyces spp. from potato field soil, (ii) develop a rapid procedure for screening strains for thaxtomin production, and (iii) compare colony morphology on our semi-selective medium, thaxtomin production, and pathogenicity of $S$. scabies and $S$. acidiscabies strains from various locations in North America.

\section{MATERIALS AND METHODS}

Streptomyces strains. We obtained approximately $70 \mathrm{~S}$. scabies and three $S$. acidiscabies strains from various locations in North America. Some of these strains

Table 1. Streptomyces strains used in this study

\begin{tabular}{ll}
\hline Strain & Source \\
\hline MSS 94-006 & MI, USA \\
MSS 94-035 & MI, USA $^{\text {b }}$ \\
MSS 95-104 & MI, USA $^{\text {b }}$ \\
MSS 95-142 & MI, USA $^{\text {b }}$ \\
DP & MI, USA $^{\text {b }}$ \\
Fi II & MI, USA $^{\text {b }}$ \\
RL 84-01-232 & USA $^{\mathrm{c}}$ \\
RL 84-01-110 & USA $^{\mathrm{c}}$ \\
RL 84-01-95 & USA $^{\mathrm{c}}$ \\
NRRL B-2796 & MT, USA $^{\mathrm{d}}$ \\
NRRL B-2801 & ME, USA $^{\mathrm{d}}$ \\
PonP & MN, USA \\
Roy & MN, USA \\
LM5MT-2 & NB, CAN \\
L89-19 & NB, CAN \\
LPit-2 & NS, CAN \\
LQH-4 & PQ, CAN \\
LR90-3 & ON, CAN \\
LWis-76-17-2 & AB, CAN \\
Warba-6 & AB, CAN \\
SP & ON, CAN \\
PP & ON, CAN \\
\hline
\end{tabular}

a Streptomyces scabies and $S$. acidiscabies (RL 84-01-110) strains from scab lesions.

${ }^{\mathrm{b}}$ Obtained from the culture collection of $\mathrm{F}$. Spooner (Michigan State University).

${ }^{c}$ Obtained from the culture collection of R. Loria (Cornell University) via F. Spooner.

${ }^{\mathrm{d}}$ Obtained from the culture collection of D. Lalseda (Microbial Properties Research, USDA, Peoria) via F. Spooner.

e Obtained from the culture collection of $\mathrm{N}$. Anderson (University of Minnesota) via F. Spooner.

${ }^{f}$ Obtained from the culture collection of $\mathrm{C} . \mathrm{H}$. Lawrence and R. R. King (AAFC, Fredericton, NB, Canada).

${ }^{\mathrm{g}}$ Isolated by the authors from site B (strain SP) and site $\mathrm{P}$ (strain PP). are listed in Table 1 along with their sources. These strains were stored as spore suspensions in $15 \%$ glycerol at $-20^{\circ} \mathrm{C}$.

Media. All reagents and antibiotics used were supplied by Sigma Chemical Co. (St. Louis, MO) unless specified otherwise. Pseudomonas agar F (PAF) medium was prepared as described by the supplier. Yeast malt extract (YME) medium and peptone-yeast extract iron (PYI) medium were prepared as described by Loria and Davis (27). To prepare oatmeal (OM) broth, rolled oats $(40 \mathrm{~g} / 600 \mathrm{ml})$ in distilled $\mathrm{H}_{2} \mathrm{O}$ were brought to a boil in a microwave oven and strained through cheesecloth, yielding $400 \mathrm{ml}$ of filtrate. One $\mathrm{ml}$ of $\mathrm{ZnSO}_{4} \cdot 7 \mathrm{H}_{2} \mathrm{O}$ stock solution $(1 \mathrm{~g} / 100 \mathrm{ml})$ was added, the volume was brought up to 1 liter, and the $\mathrm{pH}$ was adjust to 7.2 before autoclaving. OM medium (1\% agar) was also prepared.

Development of Streptomyces selective medium. Our starting point was a Streptomyces selective (STR) medium developed by G. Kritzman (Department of Plant Pathology, ARO, The Volcani Center, Bet Dagan, Israel) that he subsequently modified for isolation of Streptomyces spp. from peanuts with pod wart in Israel (19). Soil from a potato field near Alliston, Ontario (site M) was used to test STR medium for selective isolation of Streptomyces spp. from soil. Soil dilutions were plated on STR medium with the following range of $\mathrm{NaCl}$ and antibiotic concentrations: $\mathrm{NaCl}$ ( 0.5 to $3.5 \%$ ), cycloheximide (dissolved in $70 \% \mathrm{EtOH} ; 55$ to $1,300 \mathrm{ppm}$ ), nystatin $(4,420$ units/mg; dissolved in $95 \% \mathrm{EtOH}$; 2.5 to $20 \mathrm{ppm}$ ), rifampicin (dissolved in $\mathrm{MeOH}$; 0.5 to $33 \mathrm{ppm}$ ), nalidixic acid (free acid; dissolved in $0.1 \mathrm{~N} \mathrm{NaOH} ; 5.6$ to 44 $\mathrm{ppm}$ ), streptomycin sulfate (dissolved in $\mathrm{H}_{2} \mathrm{O} ; 4$ to $16 \mathrm{ppm}$ ), polymyxin $\mathrm{B}$ sulfate (dissolved in $\mathrm{H}_{2} \mathrm{O} ; 0.7$ to $11 \mathrm{ppm}$ ), and penicillin $\mathrm{G}$ (sodium salt; dissolved in $70 \%$ EtOH; 0.1 to $2.2 \mathrm{ppm}$ ). Numbers of Streptomyces, nonfilamentous bacteria, and fungi were counted after incubation for 2 weeks at $22^{\circ} \mathrm{C}$ and compared with the numbers obtained from parallel platings on PAF and YME media. Reference cultures of pathogenic $S$. scabies strains were streaked on the media to determine their growth potential. After incubation for 2 weeks at $22^{\circ} \mathrm{C}$, the extent of growth was evaluated based on the relative sizes of isolated colonies. This experiment was conducted three times. The final composition of STR medium used is (per liter of distilled $\mathrm{H}_{2} \mathrm{O}$ ): soluble potato starch, $5.0 \mathrm{~g}$; yeast extract (Difco, Detroit, MI), $4.0 \mathrm{~g}$; bacto peptone (Difco), $0.6 \mathrm{~g}$; protease peptone no. 3 (Difco), $0.6 \mathrm{~g}$; NaCl, $10 \mathrm{~g}$; $\mathrm{K}_{2} \mathrm{HPO}_{4}, 1.0 \mathrm{~g} ; \mathrm{MgSO}_{4} \cdot 7 \mathrm{H}_{2} \mathrm{O}, 0.5 \mathrm{~g}$; agar (E. Merck, Darnstadt, Germany), $17 \mathrm{~g}$; and $1 \mathrm{ml}$ of a stock solution of micro-elements comprised of $\mathrm{FeSO}_{4}, 10 \mathrm{mg} ; \mathrm{ZnSO}_{4}, 1 \mathrm{mg}$; and $\mathrm{MnCl}, 1 \mathrm{mg}$ dissolved in distilled $\mathrm{H}_{2} \mathrm{O}$. The $\mathrm{pH}$ of this medium is 7.2. Cycloheximide (200 ppm), nystatin (5.6 ppm), rifampicin (0.6 ppm), and nalidixic acid $(15 \mathrm{ppm})$ are added after sterilization. STR-M medium has the same composition as STR medium except STR-M medium contains $\mathrm{NaCl}(2 \%)$, cycloheximide (222 $\mathrm{ppm})$, nystatin (10 ppm), rifampicin (1 ppm), and nalidixic acid (22 ppm). Seven thaxtomin-producing $S$. scabies strains from site $\mathrm{M}$ were used to determine the highest concentration of $\mathrm{NaCl}$ and antibiotics that could be used to select $S$. scabies strains from soil at site M.

Isolation of Streptomyces spp. from soil. Soil samples were collected from two potato fields near Alliston, Ontario (sites $\mathrm{M}$ and $\mathrm{B}$ ). Cores to a depth of $15 \mathrm{~cm}$ were taken from 25 locations in each field and pooled. Subsamples were air-dried for 1 week, and any stones present were removed by hand. Samples (10 g) were weighed into plastic pouches $(17 \times 30 \mathrm{~cm}$; Cinran Plastics Inc., London, ON), and 90 $\mathrm{ml}$ of sterile water agar $(0.1 \% \mathrm{wt} / \mathrm{vol})$ was added. Pouches were heat sealed and shaken on an orbital shaker (200 rpm) for 2 h. Soil mixtures were then homogenized in the pouches using a Stomacher blender (Stomacher 400, Seward Medical, UK) set on normal speed for $30 \mathrm{~s}$. Serial 10-fold dilutions were prepared in saline solution $(0.85 \% \mathrm{NaCl})$. The first dilution was made in $9 \mathrm{ml}$ and the others in $900 \mu \mathrm{l}$. Aliquots $(100 \mu \mathrm{l})$ from each dilution were plated onto various media. Microbial populations in air-dried soil were compared with those in nondried soil. Isolations were made from three soil samples for each experiment, and each experiment was conducted at least three times.

Isolation of $S$. scabies from scab lesions. Scab infected tubers were collected from three potato fields near Alliston, Ontario (sites M, B, and K), a garden near Paris, Ontario (site $\mathrm{P}$ ), and a potato field near Simcoe, Ontario (site S). Potatoes were cv. Snowden for all sites except site $\mathrm{P}$, which was cv. Golden Yukon. Tubers were washed to remove soil from the lesions. Pieces of tissue from beneath lesions were excised and macerated in saline solution, and serial dilutions were plated on STR medium. Plates were incubated for 2 weeks at $22^{\circ} \mathrm{C}$. Isolations were made from two or three lesions on two or three tubers from each site.

Comparison of Streptomyces spp. on STR medium. Colony characteristics of Streptomyces spp. isolated from scab lesions and soil from Ontario potato fields were compared on STR medium. S. scabies and $S$. acidiscabies strains from scab lesions from various locations in North America were also compared on STR medium. Rate of sporulation, color, surface features, and melanin production were noted for individual colonies of each strain. Melanin production on STR medium was compared with that on PYI medium. Colonies were classified as nonsporulating if individual colonies did not form aerial 
mycelia and sporulate on STR medium within 2 weeks at $22^{\circ} \mathrm{C}$. When colony numbers were dense, forming a lawn, production of aerial mycelia and sporulation sometimes occurred; therefore, only isolated colonies were rated. Colonies were classified as smooth if they did not form aerial mycelia, sporulate, or have erupted surfaces.

Thaxtomin detection. Streptomyces strains were grown on potato tuber slices or $\mathrm{OM}$ medium for 7 to 10 days at $27^{\circ} \mathrm{C}$. A $2-\mathrm{cm}^{2}$ area of the tuber tissue or OM medium showing dense bacterial growth was cut out, placed in a 2-ml Eppendorf tube, and $1 \mathrm{ml}$ of ethyl acetate added. A toothpick was used to keep the tuber or agar pieces submerged. Thaxtomin was extracted by facilitated diffusion (12), in which Eppendorf tubes containing the tuber or medium pieces were placed in a vacuum chamber and the ethyl acetate was brought to a boil four times by repeatedly evacuating the chamber and breaking the vacuum. Pieces of tuber or medium were removed, and the volume of ethyl acetate was made up to $1.5 \mathrm{ml}$ with fresh ethyl acetate. The ethyl acetate was dried with anhydrous $\mathrm{Na}_{2} \mathrm{SO}_{4}(0.3 \mathrm{~g})$, which was then pelleted by centrifugation for $10 \mathrm{~s}$ in a microcentrifuge $(13,000 \mathrm{rpm})$. The ethyl acetate was transferred with a Pasteur pipette to a clean tube and evaporated to dryness overnight in an air stream provided by a fume hood. The residue was dissolved in $10 \mu$ l of ethyl acetate, which was collected by centrifugation for $10 \mathrm{~s}$ in a microcentrifuge. The entire extract was loaded onto E. Merck silica gel 60F thin layer chromatography (TLC) plastic plates (EM Separations Technology, Gibbstown, $\mathrm{NJ})$ cut to a dimension of $5.5 \times 7 \mathrm{~cm}$. Two outer lanes on each plate were spotted with a mixture of thaxtomin A and B standards supplied by R. R. King (AAFC, Fredericton, NB, Canada). Plates were developed in $\mathrm{CHCl}_{3}: \mathrm{MeOH}(9: 1)$ in small glass tanks. Thaxtomin A and B appear as bright yellow spots and absorb $\mathrm{UV}_{366}$ light. Occasionally, Streptomyces strains were grown in OM broth $(100 \mathrm{ml} / 250$-ml flask). These cultures were shaken on an orbital shaker $(200 \mathrm{rpm})$ for 7 to 10 days at $27^{\circ} \mathrm{C}$, filtered through glass wool, and the supernatant extracted with 2 volumes of ethyl acetate. The ethyl acetate was dried with anhydrous $\mathrm{Na}_{2} \mathrm{SO}_{4}$ and concentrated on a rotary evaporator. Presence of thaxtomins was determined by TLC.

Pathogenicity assays: Tuber slice. The procedure used was adapted from Loria et al. (25). Potato tubers, cv. Kennebec or Snowden, were peeled, sterilized in $0.05 \%$ calcium hypochlorite and $0.1 \% \mathrm{CaCO}_{3}$ for 3 min with stirring, and rinsed twice in sterile $\mathrm{H}_{2} \mathrm{O}$. Tubers were sliced into large disks with a sterile knife, and pieces $\left(2 \mathrm{~cm}^{2}\right.$ $\times 0.5 \mathrm{~cm}$ thick) from the middle of the slices were placed in sterile petri plates. Three tuber slices were used for each strain tested. A piece of medium from a zone of dense growth was cut out from Streptomyces strains grown on $\mathrm{OM}$ medium for 7 to 10 days at $27^{\circ} \mathrm{C}$. The piece of medium was then placed upside down on a tuber slice. Pieces of noninoculated OM medium were used as a control in all tests. S. scabies strains known to cause shallow necrotic lesions and deep-pitted lesions were included as positive controls. Tuber slices were placed in an incubator at $22^{\circ} \mathrm{C}$ for 3 to 6 days. Pure thaxtomin and thaxtomin extracts were applied to the surface of tuber slices as positive controls. The thaxtomin samples were first applied to sterile paper disks, the ethyl acetate was allowed to evaporate, and the disks were placed on tuber slices with a drop of sterile $\mathrm{H}_{2} \mathrm{O}$. Paper disks that had received only ethyl acetate were used as a control.

Growth of potato plants in Streptomyces-infested sand. Spores of Streptomyces strains were scraped off YME medium into YME broth $(200 \mathrm{ml})$, which was then added to $300-\mathrm{ml}$ sterile perlite in a flask. Cultures were incubated at $27^{\circ} \mathrm{C}$ for 6 weeks, mixed with sterile sand at a ratio of $10 \% \mathrm{vol} / \mathrm{vol}$, and placed in $16-\mathrm{cm}$ pots. Three pots of sand were infested for each strain tested and placed in a greenhouse in a completely randomized design. Sand containing noninoculated perlite was used

Table 2. Effect of $\mathrm{NaCl}$ and antibiotics on the growth of some pathogenic Streptomyces scabies strains ${ }^{\mathrm{a}}$

\begin{tabular}{|c|c|c|c|c|c|c|c|c|}
\hline \multirow[b]{2}{*}{ Media $^{b}$} & \multicolumn{8}{|c|}{ Relative growth of strains ${ }^{c}$} \\
\hline & SP & LM5MT-2 & L89-19 & LPit-2 & LQH-4 & LR 90-3 & LWis-76-17-2 & Warba-6 \\
\hline PAF & +++++ & +++++ & +++++ & +++++ & ++++ & +++++ & +++++ & ++++ \\
\hline YME & +++++ & +++++ & +++++ & +++++ & ++++ & +++++ & +++++ & ++++ \\
\hline \multicolumn{9}{|l|}{$\mathrm{STR}+$} \\
\hline $\mathrm{NaCl}(0.5 \%)$ & ++++ & +++ & +++ & +++ & ++ & +++ & +++ & ++ \\
\hline $\mathrm{NaCl}(1 \%)$ & ++++ & ++ & ++ & +++ & ++ & ++ & ++ & + \\
\hline $\mathrm{NaCl}(1.5 \%)$ & ++++ & + & + & ++ & + & + & + & - \\
\hline $\mathrm{NaCl}(2 \%)$ & ++++ & - & - & + & - & + & + & - \\
\hline \multicolumn{9}{|l|}{$\mathrm{STR}+\mathrm{NaCl}(1 \%)+$} \\
\hline $\mathrm{Ny}(5 \mathrm{ppm})$ & ++++ & ++ & ++ & +++ & + & ++ & ++ & + \\
\hline Ny (20 ppm) & ++++ & ++ & ++ & +++ & + & ++ & ++ & + \\
\hline Cy (110 ppm) & ++++ & ++ & ++ & +++ & + & ++ & ++ & + \\
\hline Сy $(1,300 \mathrm{ppm})$ & ++++ & ++ & ++ & +++ & + & ++ & ++ & + \\
\hline $\mathrm{Ny}(5.6 \mathrm{ppm})+\mathrm{Cy}(200 \mathrm{ppm})$ & ++++ & ++ & ++ & +++ & + & ++ & ++ & + \\
\hline \multirow{2}{*}{\multicolumn{9}{|c|}{$\begin{array}{l}\mathrm{STR}+\mathrm{NaCl}(1 \%)+ \\
\mathrm{Ny}(5.6 \mathrm{ppm})+\mathrm{Cy}(200 \mathrm{ppm})+\end{array}$}} \\
\hline & & & & & & & & \\
\hline $\mathrm{Nal}(11 \mathrm{ppm})$ & ++++ & ++ & ++ & +++ & + & ++ & ++ & + \\
\hline $\mathrm{Nal}(44 \mathrm{ppm})$ & ++++ & ++ & ++ & +++ & + & ++ & ++ & + \\
\hline $\operatorname{Rif}(0.5 \mathrm{ppm})$ & ++++ & ++ & ++ & +++ & + & ++ & ++ & + \\
\hline Rif (1 ppm) & +++ & + & ++ & ++ & - & ++ & ++ & - \\
\hline Pol (0.7 ppm) & ++++ & ++ & ++ & +++ & - & ++ & ++ & - \\
\hline Stp (4 ppm) & ++ & - & - & - & - & - & - & - \\
\hline Pen $(0.26$ ppm $)$ & ++++ & ++ & ++ & +++ & - & ++ & ++ & + \\
\hline $\begin{array}{l}\mathrm{STR}+\mathrm{NaCl}(1 \%)+\mathrm{Ny}(5.6 \mathrm{ppm})+\mathrm{Cy} \\
(200 \mathrm{ppm})+\mathrm{Nal}(15 \mathrm{ppm})+\mathrm{Rif}(0.6 \mathrm{ppm})^{\mathrm{d}}\end{array}$ & ++++ & ++ & ++ & +++ & + & ++ & ++ & + \\
\hline
\end{tabular}

${ }^{a}$ See Table 1 for sources of $S$. scabies strains.

${ }^{\text {b }}$ Pseudomonas agar F (PAF), yeast malt extract (YME), and Streptomyces selective (STR) media. Antibiotics tested were nystatin (4,420 units/mg) (Ny), cycloheximide (Cy), nalidixic acid (free acid) (Nal), rifampicin (Rif), polymyxin B sulfate (Pol), streptomycin sulfate (Stp), and penicillin G (sodium salt) (Pen). The concentrations of $\mathrm{NaCl}$ and antibiotics shown in this table are only a partial list of concentrations tested.

${ }^{c}$ Pure cultures of the $S$. scabies strains were streaked for isolated colonies on the media. The sizes of isolated colonies were compared after incubation for 2 weeks at $22^{\circ} \mathrm{C}$. A dash indicates no isolated colonies grew. Data shown are from one representative experiment. Each $\mathrm{NaCl}$ and antibiotic concentration was tested at least three times.

${ }^{d}$ This was the final combination of $\mathrm{NaCl}$ and antibiotics chosen for STR medium. Reference to STR medium in this paper indicates this medium. 
as a control. A known pathogenic $S$. scabies strain was included as a positive control. Sterile 6-week-old plantlets (cv. Kennebec) grown from nodal explants in tissue culture were planted in the pots. After 2 to 3 months, tubers were evaluated for scab symptoms. Streptomyces strains were reisolated from some of the lesions and characterized.

\section{RESULTS}

Optimizing $\mathrm{NaCl}$ and antibiotic concentrations for STR medium. There was negligible or no growth by most $S$. scabies reference strains at $1.5 \% \mathrm{NaCl}$ (Table 2). Strain SP was more resistant, being able to grow at $\mathrm{NaCl}$ concentrations up to $3 \%$. Increasing the concentration of $\mathrm{NaCl}$ from 1.0 to $1.5 \%$ reduced Streptomyces numbers from soil at site $\mathrm{M}$, whereas there was no effect on the number of culturable nonfilamentous bacteria or fungi detected (Table 3). However, $\mathrm{NaCl}$ did slow the growth rate of many nonfilamentous bacterial and fungal isolates so the $1 \% \mathrm{NaCl}$ level was kept as a component of the medium.

S. scabies reference strains grew equally well at all concentrations of nystatin and cycloheximide tested (Table 2). The higher concentrations of these antibiotics slightly reduced the number of Streptomyces spp. detected in soil (Table 3). When only these antibiotics were included in STR medium, fungal colonies could not be enumerated because they were obscured by bacterial colonies. Once the optimal combination of antibiotics was identified for reducing bacterial numbers, various combinations of nystatin and cycloheximide were tested to find the optimal concentrations for reducing fungal numbers while maintaining Streptomyces numbers constant. Nystatin at $5.6 \mathrm{ppm}$ and cycloheximide at $200 \mathrm{ppm}$ were selected for STR medium, as they reduced the number of culturable fungi detected from a potential of 300,000 $\mathrm{CFU} / \mathrm{g}$ of soil (as found on YME medium) to 3,700 CFU/g of soil (on STR medium) while the number of Streptomyces spp. was the same on both media (Table 3).

Polymyxin B, streptomycin sulfate, and penicillin $G$ were not useful for our selective medium, as at the concentrations that many $S$. scabies reference strains exhibited reduced growth (Table 2), no significant decrease in nonfilamentous bacterial numbers was found and/or the number of Streptomyces spp. was reduced (Table 3). Strain SP was more resistant to these antibiotics, showing negligible growth at 3 and 2 ppm polymyxin B and penicillin G, respectively. All $S$. scabies reference strains grew at $0.5 \mathrm{ppm}$ rifampicin (Table 2). This

Table 3. Effect of $\mathrm{NaCl}$ and antibiotics on the number of Streptomyces, nonfilamentous bacteria, and fungi isolated from a potato field soil near Alliston, Ontario (site M)

\begin{tabular}{|c|c|c|c|}
\hline \multirow[b]{2}{*}{ Media $^{a}$} & \multicolumn{3}{|c|}{$\mathrm{CFU} / \mathrm{g}$ soil $\times 1,000^{\mathrm{b}}$} \\
\hline & Streptomyces bacteria & Nonfilamentous bacteria & Fungi \\
\hline PAF & $1,000 \pm 33$ & $21,000 \pm 4,000$ & $-^{\mathrm{c}}$ \\
\hline YME & $1,000 \pm 200$ & $9,000 \pm 2,500$ & $300 \pm 0.0$ \\
\hline \multicolumn{4}{|l|}{ STR + } \\
\hline $\mathrm{NaCl}(0.5 \%)$ & $1,600 \pm 720$ & $5,000 \pm 2,500$ & $150 \pm 50$ \\
\hline $\mathrm{NaCl}(1 \%)$ & $1,100 \pm 470$ & $8,700 \pm 1,800$ & $67 \pm 20$ \\
\hline $\mathrm{NaCl}(1.5 \%)$ & $470 \pm 67$ & $8,700 \pm 2,200$ & $130 \pm 33$ \\
\hline $\mathrm{NaCl}(2 \%)$ & $330 \pm 120$ & $5,900 \pm 2,100$ & $120 \pm 39$ \\
\hline \multicolumn{4}{|l|}{$\mathrm{STR}+\mathrm{NaCl}(1 \%)+$} \\
\hline Ny $(5 \mathrm{ppm})$ & $900 \pm 120$ & $8,000 \pm 1,200$ & - \\
\hline Ny (20 ppm) & $630 \pm 180$ & $12,000 \pm 1,900$ & - \\
\hline Cy (110 ppm) & $1,700 \pm 330$ & $14,000 \pm 4,400$ & - \\
\hline $\mathrm{Cy}(1,300 \mathrm{ppm})$ & $1,000 \pm 380$ & $7,000 \pm 1,500$ & - \\
\hline $\mathrm{Ny}(5.6 \mathrm{ppm})+\mathrm{Cy}(200 \mathrm{ppm})$ & $830 \pm 200$ & $8,300 \pm 1,900$ & - \\
\hline \multicolumn{4}{|l|}{$\mathrm{STR}+\mathrm{NaCl}(1 \%)+$} \\
\hline \multicolumn{4}{|l|}{$\mathrm{Ny}(5.6 \mathrm{ppm})+\mathrm{Cy}(200 \mathrm{ppm})+$} \\
\hline $\mathrm{Nal}(11 \mathrm{ppm})$ & $1,500 \pm 58$ & $4,800 \pm 420$ & - \\
\hline $\mathrm{Nal}$ (44 ppm) & $1,300 \pm 220$ & $4,500 \pm 490$ & - \\
\hline $\operatorname{Rif}(0.5 \mathrm{ppm})$ & $1,000 \pm 180$ & $700 \pm 200$ & - \\
\hline $\operatorname{Rif}(1 \mathrm{ppm})$ & $700 \pm 250$ & $500 \pm 0.0$ & - \\
\hline Pol (0.7 ppm) & $1,300 \pm 200$ & $14,000 \pm 6,800$ & - \\
\hline Stp (4 ppm) & $400 \pm 150$ & $4,300 \pm 1,400$ & - \\
\hline Pen $(0.26 \mathrm{ppm})$ & $900 \pm 150$ & $4,400 \pm 260$ & - \\
\hline \multicolumn{4}{|c|}{$\begin{array}{l}\mathrm{STR}+\mathrm{NaCl}(1 \%)+\mathrm{Ny}(5.6 \mathrm{ppm})+ \\
\mathrm{Cy}(200 \mathrm{ppm})+\mathrm{Nal}(15 \mathrm{ppm})+\end{array}$} \\
\hline Rif $(0.6 \mathrm{ppm})^{\mathrm{d}}$ & $1,100 \pm 120$ & $160 \pm 65$ & $3.7 \pm 2.2$ \\
\hline
\end{tabular}

a Pseudomonas agar F (PAF), yeast malt extract (YME), and Streptomyces selective (STR) media. Antibiotics tested were nystatin (4,420 units/mg) (Ny), cycloheximide (Cy), nalidixic acid (free acid) (Nal), rifampicin (Rif), polymyxin B sulfate (Pol), streptomycin sulfate (Stp), and penicillin G (sodium salt) (Pen). The concentrations of $\mathrm{NaCl}$ and antibiotics shown in this table are only a partial list of concentrations tested.

${ }^{b}$ Means ( \pm standard error of the mean) were determined from three soil samples.

${ }^{c}$ Number of fungi could not be determined because fungal colonies were obscured by bacterial colonies.

d This was the final combination of $\mathrm{NaCl}$ and antibiotics chosen for STR medium. Reference to STR medium in this paper indicates this medium. concentration of rifampicin reduced the number of nonfilamentous bacteria detected from a potential of 21 million $\mathrm{CFU} / \mathrm{g}$ of soil (as found on PAF medium) to $700,000 \mathrm{CFU} / \mathrm{g}$ of soil while having no effect on the number of Streptomyces spp. detected (Table 3). Rifampicin thus provided a significant selection for Streptomyces spp. All S. scabies reference strains grew equally well at 11 and $44 \mathrm{ppm}$ nalidixic acid (Table 2). These concentrations of nalidixic acid reduced the soil nonfilamentous bacterial numbers detected while not reducing the Streptomyces numbers (Table 3). Nalidixic acid was considered a valuable component of STR medium, as it also reduced the colony size of many bacteria. A nalidixic acid concentration of $15 \mathrm{ppm}$ was chosen for STR medium because the 44-ppm concentration did not reduce the nonfilamentous bacterial numbers any further (Table 3 ).

All $S$. scabies reference strains grew at the concentrations of $\mathrm{NaCl}$ and the mixture of antibiotics selected for STR medium (Table 2). STR medium will refer to this combination of $\mathrm{NaCl}$ and antibiotics. The number of Streptomyces detected on the final STR medium was the same as found on PAF and YME media tested (Table 3). The number of nonfilamentous bacteria, however, was reduced from a potential of 21 million CFU/g of soil (as detected on PAF medium) to $160,000 \mathrm{CFU} / \mathrm{g}$ of soil on STR medium (Table 3). Thus, for this particular soil sample, the numbers of Streptomyces and nonfilamentous bacteria detected on PAF medium at the $10^{-5}$ dilution were 10 and 210, respectively. Below this dilution, it was practically impossible to find any Streptomyces spp., as they were obscured by nonfilamentous bacteria. In contrast, on STR medium at the $10^{-4}$ dilution, the numbers of Streptomyces and nonfilamentous bacteria detected were 100 and 16, respectively. This allowed for detection of Streptomyces spp. at the $10^{-4}$ and $10^{-3}$ dilutions (Fig. 1). On STR medium, the number of fungi detected was 3,700 CFU/g of soil compared with 300,000 $\mathrm{CFU} / \mathrm{g}$ of soil on YME medium (Table 3 ), which virtually prohibited any fungal contaminants from interfering with enumeration of Streptomyces spp. Air-drying of the soil before plating also helped reduce the number of nonfilamentous bacteria detected while having no effect on the number of Streptomyces spp.

Thaxtomin detection. Small TLC plates $(5.5 \times 7 \mathrm{~cm}$ cut from $20 \times 20 \mathrm{~cm}$ TLC sheets) were used to detect thaxtomin, which allowed 90 samples to be run on a $20 \times 20 \mathrm{~cm}$ TLC sheet. These small TLC plates required only $6 \mathrm{~min}$ to develop in very small volumes of solvent and allowed for the detection of smaller amounts of toxin than on larger TLC plates. Thaxtomin $\mathrm{A}$ and $\mathrm{B}$ were easily recognized on plates based on their $R_{f}$ values compared with standards, their bright yellow color, 
which remained stable for months, and their absorbance of $\mathrm{UV}_{366}$ light. Other yellow pigments encountered from various strains did not have all three of these properties. Thaxtomin was detected by this procedure from Streptomyces-inoculated $\mathrm{OM}$ medium as well as from inoculated tuber slices.

Extracts containing yellow components corresponding to thaxtomin A or B were tested for phytotoxicity using the tuber slice assay. Such extracts produced symptoms identical to pure thaxtomin A or B, confirming the accurate identification of thaxtomin by TLC. Extracts from nonthaxtomin-producing strains caused no symptoms on tuber slices. To determine if this extraction and detection procedure missed any strains producing low amounts of thaxtomin, a number of strains identified as thaxtomin deficient when grown on $\mathrm{OM}$ medium (Tables 4 and 5) were tested for thaxtomin production in OM broth (100 $\mathrm{ml})$. All strains that did not produce thaxtomin on OM medium did not produce it in $\mathrm{OM}$ broth either. These strains were also tested on potato tuber slices to determine if they produced thaxtomin on tuber slices but not on OM medium. All strains that did not produce thaxtomin on OM medium did not produce it on tuber slices either. Inclu- sion of an $S$. scabies or S. acidiscabies strain known to produce thaxtomin, as a positive control, is recommended and was routinely done in our screening. With this procedure, one person can easily screen 50 strains over the 2-day extraction and detection process.

Characteristics of Streptomyces spp. on STR medium. Streptomyces spp. grown on STR medium could be readily identified by a distinct circular depression in the medium at the edges of the colonies. This depression was most apparent when plates were examined at a slight angle. Streptomyces spp. formed colonies that were hard and adhered strongly to the medium. Most colonies formed aerial mycelia and sporulated on STR medium. However, all pathogenic $S$. scabies reference strains (Table 2) either did not form aerial mycelia and sporulate on STR medium when incubated at $22^{\circ} \mathrm{C}$ or were slow to do so. If STR medium was inoculated with very large numbers of bacteria, the lawn that arose sometimes showed sporulation, but individual colonies never formed aerial mycelia and sporulated within 2 weeks at $22^{\circ} \mathrm{C}$. Most of these strains sporulated on STR medium if incubated at higher temperatures. All thaxtomin-producing strains isolated from scab lesions or soil from five locations in Ontario had the nonsporulating (NS) colony phenotype on STR medium (Table 4). In addition, all these colonies were smooth, brown, and produced melanin $\left(\mathrm{Mel}^{+}\right)$(Table 4; Fig. 1). Many of the strains were grown on PYI medium to test for melanin production. Only those that produced melanin on STR medium produced it on PYI medium. These NS colonies could be detected on STR medium after 3 to 4 days along with the presence of melanin. All strains with this colony morphology from scab lesions produced thaxtomin A (Table 4). Thaxtomin-producing strains from soil were also of the same phenotype, but not all strains with this colony morphology produced thaxtomin (Table 4). Only 7 and $9 \%$ of strains with this colony morphology isolated from soil at sites $\mathrm{M}$ and $\mathrm{B}$, respectively, produced thaxtomin A (Table 4).

Comparison of some North American $S$. scabies and $S$. acidiscabies strains. Comparison of colony morphology on STR medium, thaxtomin production, and pathogenicity of some North American S. scabies and $S$. acidiscabies strains is shown in Table 5. All strains grew on STR medium. All strains that produced thaxtomin had smooth NS colonies on STR medium (Table 5). Most of the S. scabies strains
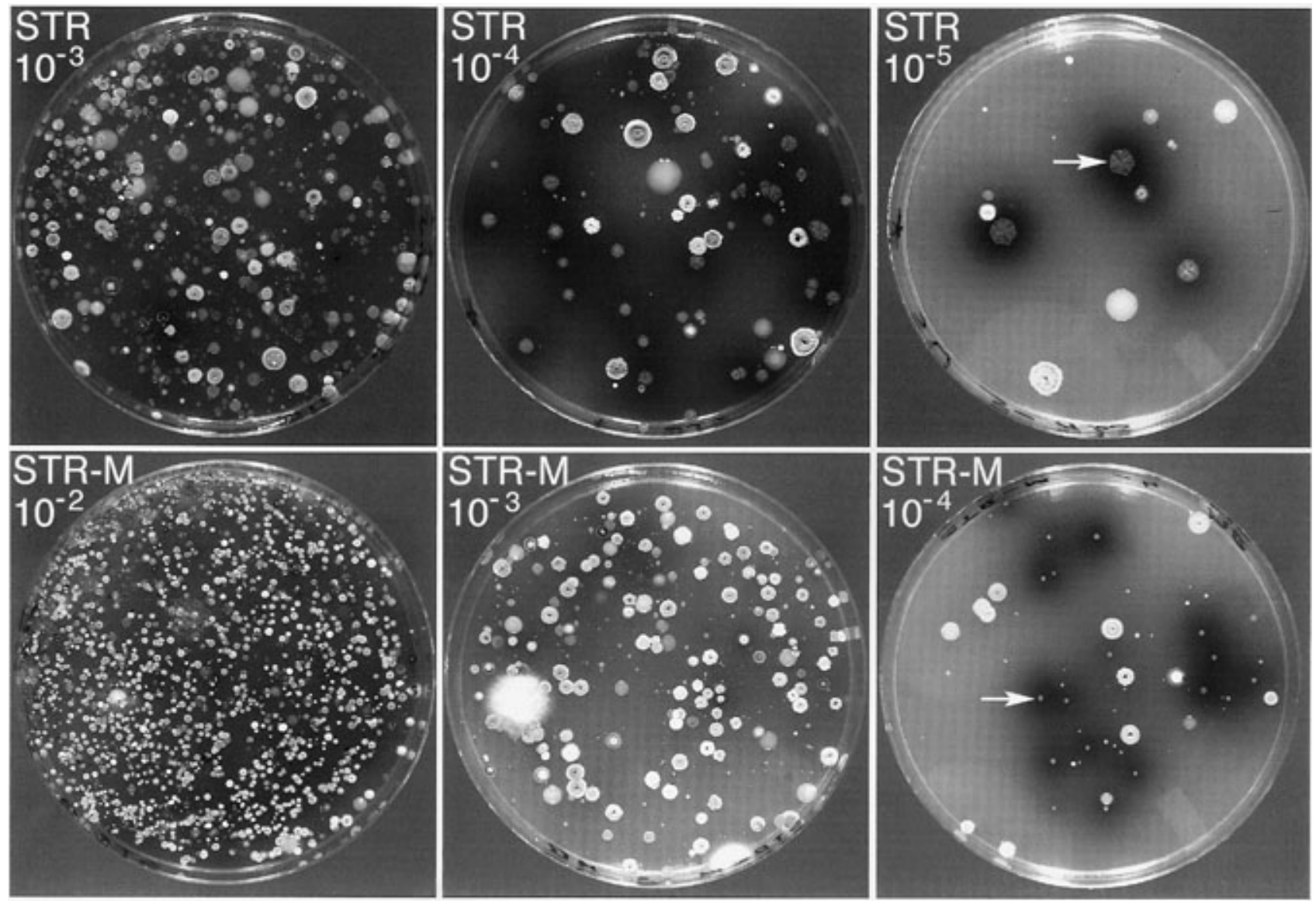

Fig. 1. Isolation of Streptomyces spp. on a semi-selective culture (STR) and STR-M media from a potato field soil near Alliston, Ontario (site M). STR-M medium had higher concentrations of $\mathrm{NaCl}$ and antibiotics than STR medium and was specifically designed for isolation of $S$. scabies from soil from site M. Note that the majority of colonies on these media are Streptomyces bacteria. S. scabies colonies that produce thaxtomin are characterized by the presence of melanin and lack of aerial mycelia and sporulation (arrows). Photographs were taken after plates had been incubated for 2 weeks at $22^{\circ} \mathrm{C}$. 
produced melanin, with the exception of some from Michigan (Table 5). Tests of selected strains for pathogenicity using the tuber slice assay revealed a positive correlation between thaxtomin production and necrotic symptoms on tuber slices (Table 5). Two types of symptoms were observed: one was necrosis of cells around the inoculation site identical to that induced by thaxtomin, and the other was a deep-pitted lesion in the tuber slice. There were a few Streptomyces strains from soil that did not produce thaxtomin but caused deep-pitted lesions on tuber slices. These strains failed to cause any lesions on tubers when tested in the greenhouse assay. Only thaxtominproducing strains caused scab symptoms on potato tubers grown under greenhouse conditions (Table 5). Symptoms varied from shallow to deep-pitted lesions. Some thaxtomin-producing strains did not cause scab symptoms in the greenhouse assay (Table 5).

Quantifying thaxtomin-producing $S$. scabies in soil. Soil from a potato field near Alliston, Ontario (site M) was plated on STR and STR-M media, and the smooth, brown, $\mathrm{Mel}^{+}$, NS colonies were transferred onto $\mathrm{OM}$ medium. These strains were then tested for thaxtomin production. The number of Streptomyces detected on STR medium was 1.4 million CFU/g of soil (Table 6). Of these, the Streptomyces spp. with the NS colony phe- notype represented just under half the population, i.e., $570,000 \mathrm{CFU} / \mathrm{g}$ of soil (Table 6). Four percent (3/75) of this group produced thaxtomin, which translated to 23,000 CFU/g of soil. On STR-M medium, the number of Streptomyces detected was reduced to $350,000 \mathrm{CFU} / \mathrm{g}$ of soil, and of these, 130,000 CFU/g of soil had the NS colony phenotype (Table 6; Fig. 1). Fifteen percent $(8 / 54)$ of colonies with the NS phenotype produced thaxtomin. Thus, the number of thaxtomin-producing Streptomyces spp. was $19,000 \mathrm{CFU} / \mathrm{g}$ of soil, which was not significantly different from that calculated on STR medium (Table 6).

\section{DISCUSSION}

We developed a culture medium that provides selective isolation of Streptomyces spp. from soils where potatoes are grown. STR medium reduces the number of unwanted bacteria and fungi on soil dilution plates to levels below that of Streptomyces spp., while not affecting the number of Streptomyces detected compared with that on PAF or YME media. In addition, the medium allows colonies to express a phenotype (smooth NS) that helps identify potential pathogenic $S$. scabies strains. All pathogenic $S$. scabies and $S$. acidiscabies reference strains we screened had this colony phenotype on STR medium. All pathogenic $S$. scabies strains we isolated from scab lesions or soils from

Table 4. Colony characteristics on Streptomyces selective (STR) medium and thaxtomin production by Streptomyces spp. isolated from scab lesions and soil in Ontario

\begin{tabular}{|c|c|c|c|c|c|}
\hline $\begin{array}{l}\text { Source of } \\
\text { isolates }^{\mathrm{a}}\end{array}$ & $\begin{array}{l}\text { Sporulation } \\
\text { of colonies }\end{array}$ & $\begin{array}{l}\text { Colony } \\
\text { color }\end{array}$ & $\begin{array}{c}\text { Melanin } \\
\text { production }^{\mathrm{c}}\end{array}$ & $\begin{array}{c}\text { Colony } \\
\text { surface }^{d}\end{array}$ & $\begin{array}{c}\text { Thaxtomin A } \\
\text { production/totale }\end{array}$ \\
\hline \multicolumn{6}{|l|}{ Site M } \\
\hline Scab lesions & NS & Brown & + & Smooth & $9 / 9$ \\
\hline \multirow[t]{3}{*}{ Soil } & NS & Brown & + & Smooth & $5 / 72$ \\
\hline & NS & Yellow & - & Smooth & $0 / 18$ \\
\hline & Sporulated & Various & $+\&-$ & Powdery & $0 / 119$ \\
\hline \multicolumn{6}{|l|}{ Site B } \\
\hline Scab lesions & NS & Brown & + & Smooth & $6 / 6$ \\
\hline \multirow{5}{*}{ Soil } & NS & Brown & + & Smooth & $4 / 44$ \\
\hline & NS & Yellow & - & Smooth & $0 / 33$ \\
\hline & NS & Red & + & Smooth & $0 / 2$ \\
\hline & NS & Yellow & - & Erupted & $0 / 76$ \\
\hline & Sporulated & Various & $+\&-$ & Powdery & $0 / 60$ \\
\hline \multicolumn{6}{|l|}{ Site $\mathrm{P}$} \\
\hline Scab lesions & NS & Brown & + & Smooth & $48 / 48$ \\
\hline \multicolumn{6}{|l|}{ Site $S$} \\
\hline Scab lesions & NS & Brown & + & Smooth & $44 / 44$ \\
\hline \multicolumn{6}{|l|}{ Site K } \\
\hline Scab lesions & NS & Brown & + & Smooth & $12 / 12$ \\
\hline
\end{tabular}

${ }^{a}$ Isolated on STR medium from five locations in Ontario.

${ }^{\mathrm{b}}$ Colonies were classified as nonsporulating (NS) if individual colonies did not form aerial mycelia and sporulate on STR medium within 2 weeks at $22^{\circ} \mathrm{C}$. If colony numbers were dense, forming a lawn, production of aerial mycelia and sporulation sometimes occurred, so only isolated colonies were rated.

${ }^{c}$ Melanin production on STR medium. These results were the same as those on peptone-yeast extract iron medium.

${ }^{\mathrm{d}}$ Colonies were classified as smooth if they did not form aerial mycelia, sporulate, or have erupted surfaces.

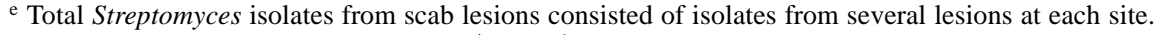
All Streptomyces colonies from the $10^{-4}$ to $10^{-6}$ dilution plates from soil were tested. Thaxtomin A production was determined by growing the isolates on oatmeal medium, extraction of thaxtomin, and detection by thin layer chromatography. None of the isolates listed produced detectable amounts of thaxtomin B.
Ontario produced melanin, which narrowed the phenotype even further. Since melanin production can be detected on STR medium, this eliminates the need to screen strains on PYI medium. Production of melanin has been used as a diagnostic characteristic of S. scabies (14). However, some other Streptomyces spp. also produce melanin (Table 4), and not all pathogenic $S$. scabies strains in North America produce melanin (Table 5). Thus, melanin production by itself cannot be used as a diagnostic characteristic of pathogenicity of S. scabies.

After we were able to isolate Streptomyces spp. from soil, we needed a simple procedure to screen hundreds of strains for thaxtomin production. We developed a procedure that allows for rapid extraction of thaxtomin from small amounts of inoculated $\mathrm{OM}$ medium and uses minimum solvent volumes and low-cost Eppendorf tubes. Advantages of using inoculated OM medium over tuber slices for detection of thaxtomin are that the medium is easier to prepare and the extracts produce cleaner chromatograms. To confirm thaxtomin production by $S$. ipomoeae, however, tuber slices would be required, since S. ipomoeae does not produce thaxtomin on OM medium (16). We did not test any strains of this species. Using this procedure, we found that all $S$. scabies strains with the smooth NS colony phenotype that we isolated from potato scab lesions produced thaxtomin A. However, only 4 to $9 \%$ of $S$. scabies strains from soil with this colony morphology produced thaxtomin A. This is a similar result to that found by Keinath and Loria (13) in which only 3.3\% of $S$. scabies strains isolated from a soil were found to be pathogenic. The positive correlation between thaxtomin production and smooth NS colonies on STR medium means that only these colonies need to be tested for thaxtomin production and for further characterization. We have not determined yet if all Streptomyces colonies with the smooth NS phenotype isolated from these soils are $S$. scabies or a mixture of Streptomyces spp. However, all S. scabies reference strains producing thaxtomin that we tested had this colony phenotype.

All thaxtomin-producing S. scabies and $S$. acidiscabies strains that we tested caused symptoms on tuber slices. There were a few strains from soil that did not produce thaxtomin but caused deep-pitted lesions on tuber slices. S. scabies strains that produce thaxtomin and cause deeppitted lesions must be producing various enzymes to create such lesions. A positive correlation between production of hydrolytic enzymes and the ability to cause deep-pitted lesions has been demonstrated $(6,9)$. It is not surprising that some strains that do not produce thaxtomins, but may produce hydrolytic enzymes, can also cause lesions on tuber slices. However, only thaxtomin-producing Streptomyces 
strains caused scab symptoms on potato tubers grown under greenhouse conditions. Some thaxtomin-producing $S$. scabies strains did not cause symptoms on tubers grown in the greenhouse. We do not know whether this was due to loss of pathogenicity, poor survival, or inappropriate environmental conditions. The most serious problem with the greenhouse assay is maintaining optimal soil moisture levels for infection by $S$. scabies. Reports from the literature suggest that dry soil conditions provide optimal infection conditions for $S$. scabies $(11,20)$. Plants in the greenhouse were watered every 2 to 3 days, so the soil was wet more than it was dry. The fact that strain SP caused deep-pitted lesions every time we tested it suggests that environmental conditions are not critical to all strains. These experiments reveal, however, that pathogenicity assays utilizing tuber slices or growing plants in the greenhouse are not totally reliable for distinguishing pathogenic from nonpathogenic strains. This was one of the reasons we chose to use thaxtomin production as a pathogenicity marker in our screening of Streptomyces strains.

Using STR and STR-M media along with our procedure for detection of thaxtomin, we determined that the number of thaxtomin-producing $S$. scabies in soil from a potato field in Ontario with a his- tory of potato scab was about 20,000 $\mathrm{CFU} / \mathrm{g}$ of soil. Use of STR-M medium reduced the number of Streptomyces colonies with the smooth NS phenotype that needed to be screened for thaxtomin production. This demonstrates that STR medium can be modified to increase the relative proportion of pathogenic Streptomyces strains from specific soils. Use of higher levels of $\mathrm{NaCl}$ could certainly be exploited for isolating S. scabies from certain soils, because some strains have higher tolerances to salt than the ones we isolated. For example, $40 \%$ of $S$. scabies strains from
Quebec grew at $4 \% \mathrm{NaCl}(5), 83 \%$ of strains from a variety of locations grew at $5 \% \mathrm{NaCl}(21)$, and $100 \%$ of strains from a Minnesota location grew at $6 \% \mathrm{NaCl}(24)$. Modification of STR medium will not necessarily provide better isolation of $S$. scabies from every soil, however. We tested STR-M medium for quantifying $S$. scabies from soil from site B. Pathogenic $S$. scabies reference strains from this site grew on STR-M medium, and the number of colonies from soil with the smooth NS phenotype was decreased. However, this soil contained a Streptomyces sp. that was

Table 6. Quantifying Streptomyces bacteria from a potato field soil near Alliston, Ontario (site M) and determination of the number producing thaxtomin

\begin{tabular}{|c|c|c|c|}
\hline \multirow[b]{2}{*}{ Media $^{a}$} & \multicolumn{3}{|c|}{ Streptomyces $(\mathrm{CFU} / \mathrm{g} \text { soil } \times 1,000)^{\mathrm{b}}$} \\
\hline & Total & $\mathrm{Mel}^{+}, \mathrm{NS}^{\mathrm{c}}$ & Thaxtomin producing ${ }^{d}$ \\
\hline $\begin{array}{l}\text { STR } \\
\text { STR-M }\end{array}$ & $\begin{array}{c}1,400 \pm 370 \\
350 \pm 18\end{array}$ & $\begin{array}{c}570 \pm 220 \\
130 \pm 3.3\end{array}$ & $\begin{array}{l}23 \pm 8.6 \\
19 \pm 0.3\end{array}$ \\
\hline \multicolumn{4}{|c|}{$\begin{array}{l}\text { STR = Streptomyces selective medium. STR-M medium had higher concentrations of } \mathrm{NaCl} \text { and } \\
\text { antibiotics than STR medium and was specifically designed for isolation of S. scabies from soil } \\
\text { from site M. } \\
\text { b Means ( } \pm \text { standard error of the mean) were determined from three soil samples. } \\
\text { c This group of Streptomyces bacteria contains } S \text {. scabies strains. These bacterial colonies produced } \\
\text { melanin }\left(\mathrm{Mel}^{+} \text {) and did not form aerial mycelia or sporulate (NS) on STR or STR-M medium when }\right. \\
\text { incubated at } 22^{\circ} \mathrm{C} \text {. } \\
\text { dhe number of } S \text {. scabies strains that produced thaxtomin was determined by growing } \mathrm{Mel}^{+}, \mathrm{NS} \\
\text { colonies on oatmeal medium, extraction of thaxtomin, and detection by thin layer chromatography } \\
\text { The number of Streptomyces with } \mathrm{Mel}^{+} \text {, NS colonies was then multiplied by the percentage of } \\
\text { thaxtomin producers to get the number of thaxtomin-producing } S \text {. scabies/g of soil. }\end{array}$} \\
\hline
\end{tabular}

Table 5. Colony characteristics on Streptomyces selective (STR) medium, thaxtomin production, and pathogenicity of some North American Streptomyces scabies and $S$. acidiscabies strains

\begin{tabular}{|c|c|c|c|c|c|c|c|}
\hline \multirow[b]{2}{*}{ Strain $^{a}$} & \multirow[b]{2}{*}{$\begin{array}{l}\text { Sporulation } \\
\text { of colonies }^{b}\end{array}$} & \multirow[b]{2}{*}{$\begin{array}{c}\text { Colony } \\
\text { color }\end{array}$} & \multirow[b]{2}{*}{$\begin{array}{c}\text { Melanin } \\
\text { production }^{c}\end{array}$} & \multirow[b]{2}{*}{$\begin{array}{c}\text { Colony } \\
\text { surface }^{d}\end{array}$} & \multirow[b]{2}{*}{$\begin{array}{l}\text { Thaxtomin } \\
\text { production }^{\mathrm{e}}\end{array}$} & \multicolumn{2}{|c|}{ Pathogenicity $\mathrm{f}$} \\
\hline & & & & & & $\begin{array}{c}\text { Tuber } \\
\text { slice }\end{array}$ & $\begin{array}{c}\text { Greenhouse } \\
\text { tubers }\end{array}$ \\
\hline MSS 94-006 & NS & Brown & + & Smooth & A & + & + \\
\hline MSS 94-035 & Sporulated & Yellow & - & Powdery & - & - & - \\
\hline MSS 95-104 & NS & Brown & + & Smooth & A & + & NT \\
\hline MSS 95-142 & NS & Yellow & - & Smooth & A & + & NT \\
\hline $\mathrm{DP}$ & NS & Yellow & - & Smooth & A & + & + \\
\hline Fi II & NS & Brown & + & Smooth & - & - & - \\
\hline RL 84-01-232 & NS & Brown & + & Smooth & A & + & - \\
\hline RL 84-01-110 & NS & Yellow & - & Smooth & $\mathrm{A}, \mathrm{B}$ & + & + \\
\hline RL 84-01-95 & Sporulated & Yellow & + & Powdery & - & - & - \\
\hline NRRL B-2796 & NS & Brown & + & Smooth & A & + & + \\
\hline NRRL B-2801 & Sporulated & Yellow & + & Powdery & - & - & - \\
\hline PonP & NS & Brown & + & Smooth & A & + & + \\
\hline Roy & NS & Brown & + & Smooth & A & + & - \\
\hline LM5MT-2 & NS & Yellow & + & Smooth & A & + & NT \\
\hline L89-19 & NS & Yellow & + & Smooth & A & + & - \\
\hline LPit-2 & NS & Yellow & + & Smooth & A & + & NT \\
\hline LQH-4 & NS & Yellow & + & Smooth & A & + & + \\
\hline LR90-3 & NS & Yellow & + & Smooth & A & + & + \\
\hline LWis-76-17-2 & NS & Yellow & + & Smooth & A & + & NT \\
\hline Warba-6 & NS & Yellow & - & Smooth & A & + & NT \\
\hline SP & NS & Brown & + & Smooth & A & + & + \\
\hline PP & NS & Brown & + & Smooth & A & + & + \\
\hline
\end{tabular}

a S. scabies and S. acidiscabies (RL 84-01-110) strains from scab lesions. See Table 1 for sources of strains.

${ }^{\mathrm{b}}$ Colonies were classified as nonsporulating (NS) if individual colonies did not form aerial mycelium and sporulate on STR medium within 2 weeks at $22^{\circ} \mathrm{C}$. If colony numbers were dense, forming a lawn, production of aerial mycelium and sporulation sometimes occurred so only isolated colonies were rated.

c Melanin production on STR medium. These results were the same as those on peptone-yeast extract iron medium.

${ }^{\mathrm{d}}$ Colonies were classified as smooth if they did not form aerial mycelia, sporulate, or have erupted surfaces.

e Production of thaxtomins A and B determined by growing isolates on oatmeal medium, extraction of thaxtomin, and detection by thin layer chromatography.

$\mathrm{f}+=$ shallow or deep-pitted lesions. $-=$ no lesions. NT $=$ not tested. 
present in high numbers and was not inhibited by this medium. Thus, the colonies with the smooth NS phenotype were obscured by colonies of this Streptomyces sp., which prevented their enumeration. We believe, however, that STR medium, or modifications, and the thaxtomin detection procedure described will be useful for investigations into population dynamics of pathogenic Streptomyces in soil.

\section{ACKNOWLEDGMENTS}

We thank J. Kers, B. Aukema, J. Green, and S. Allan for their technical assistance. We also wish to express our appreciation to R. R. King for providing authentic samples of thaxtomin $\mathrm{A}$ and $\mathrm{B}$, to C. H. Lawrence and R. R. King for S. scabies strains, and to F. Spooner for S. scabies and S. acidiscabies strains from his and other researchers' collections. This research was supported by the Fats and Proteins Foundation, Canada-Ontario Agriculture Green Plan, and the South Simcoe Potato Growers Association.

\section{LITERATURE CITED}

1. Babcock, M. J., Eckwall, E. C., and Schottel, J. L. 1993. Production and regulation of potato-scab-inducing phytotoxins by Streptomyces scabies. J. Gen. Microbiol. 139:15791586.

2. Davies, F. L., and Williams, S. T. 1970. Studies on the ecology of actinomycetes in soil. I. The occurrence and distribution of actinomycetes in a pine forest soil. Soil Biol. Biochem. 2:227-238.

3. DeKlerk, A., McLeod, A., Faurie, R., Swart, W. J., and Denner, F. D. N. 1996. Identification and toxin production of Streptomyces isolates responsible for common scab in the northern Cape Province of South Africa. Proc. Eur. Assoc. Potato Res. Trienn. Conf., 13th. Veldhoven, The Netherlands.

4. Doering-Saad, C., Kämpfer, P., Shulamit, M., Kritzman, G., Schneider, J., ZakrzewskaCzerwinska, J., Schrempf, H., and Barash, I. 1992. Diversity among Streptomyces strains causing potato scab. Appl. Environ. Microbiol. 58:3932-3940.

5. Faucher, E., Otrysko, B., Paradis, E., Hodge, N. C., Stall, R. E., and Beaulieu, C. 1993. Characterization of streptomycetes causing russet scab in Québec. Plant Dis. 77:12171220.
6. Faucher, E., Paradis, E., Goyer, C., Hodge, N. C., Hogue, R., Stall, R. E., and Beaulieu, C. 1995. Characterization of streptomycetes causing deep-pitted scab of potato in Québec, Canada. Int. J. Syst. Bacteriol. 45:222-225.

7. Faucher, E., Savard, T., and Bealieu, C. 1992. Characterization of actinomycetes isolated from common scab lesions on potato tubers. Can. J. Plant Pathol. 14:197-202.

8. Goyer, C., and Beaulieu, C. 1997. Host range of streptomycete strains causing common scab. Plant Dis. 81:901-904.

9. Goyer, C., Otrysko, B., and Beaulieu, C. 1996. Taxonomic studies on streptomycetes causing potato common scab: A review. Can. J. Plant Pathol. 18:107-113.

10. Healy, F. G., and Lambert, D. H. 1991. Relationships among Streptomyces spp. causing potato scab. Int. J. Syst. Bacteriol. 41:479482.

11. Hooker, W. J. 1981. Common scab. Pages 3334 in: Compendium of Potato Diseases. W. J. Hooker, ed. American Phytopathological Society, St. Paul, MN.

12. Keen, N. T. 1978. Phytoalexins: Efficient extraction from leaves by a facilitated diffusion technique. Phytopathology 68:12371239.

13. Keinath, A. P., and Loria, R. 1989. Population dynamics of Streptomyces scabies and other actinomycetes as related to common scab of potato. Phytopathology 79:681-687.

14. Keinath, A. P., and Loria, R. 1990. Melaninproducing Streptomyces spp. respond to potato plant growth and differentially to potato cultivars. Can. J. Microbiol. 36:279-285.

15. King, R. R., and Lawrence, C. H. 1996. Characterization of new thaxtomin A analogs generated in vitro by Streptomyces scabies. J. Agric. Food Chem. 44:1108-1110.

16. King, R. R., Lawrence, C. H., Calhoun, L. A., and Ristaino, J. B. 1994. Isolation and characterization of thaxtomin-type phytotoxins associated with Streptomyces ipomoeae. J. Agric. Food Chem. 42:1791-1794.

17. King, R. R., Lawrence, C. H., and Clark, M. C. 1991. Correlation of phytotoxin production with pathogenicity of Streptomyces scabies isolates from scab infected potato tubers. Am. Potato J. 68:675-680.

18. Kritzman, G., and Grinstein, A. 1991. Formalin application against soil-borne streptomyces. Phytoparasitica 19:248.

19. Kritzman, G., Shani-Cahani, A., Kirshner, B.,
Riven, Y., Bar, Z., Katan, J., and Grinstein, A. 1996. Pod wart disease of peanuts. Phytoparasitica 24:293-304.

20. Labruyère, R. E. 1971. Common scab and its control in seed-potato crops. Meded. Inst. Plantenziekten. Onderz. 575.

21. Lambert, D. H., and Loria, R. 1989. Streptomyces scabies sp. nov., nom. rev. Int. J. Syst. Bacteriol. 39:387-392.

22. Lawrence, C. H., Clark, M. C., and King, R. R. 1990. Induction of common scab symptoms in aseptically cultured potato tubers by the vivo-toxin, thaxtomin. Phytopathology 80:606-608.

23. Leiner, R. H., Fry, B. A., Carling, D. E., and Loria, R. 1996. Probable involvement of thaxtomin A in pathogenicity of Streptomyces scabies on seedlings. Phytopathology 86:709713.

24. Lorang, J. M., Liu, D., Anderson, N. A., and Schottel, J. L. 1995. Identification of potato scab inducing and suppressive species of Streptomyces. Phytopathology 85:261-268.

25. Loria, R., Bukhalid, R. A., Creath, R. A., Leiner, R. H., Olivier, M., and Steffens, J. C. 1995. Differential production of thaxtomins by pathogenic Streptomyces species in vitro. Phytopathology 85:537-541.

26. Loria, R., Bukhalid, R. A., Fry, B. A., and King, R. R. 1997. Plant pathogenicity in the genus Streptomyces. Plant Dis. 81:836-846.

27. Loria, R., and Davis, J. R. 1988. Streptomyces scabies. Pages 114-119 in: Laboratory Guide for Identification of Plant Pathogenic Bacteria. N. W. Schaad, ed. American Phytopathological Society, St. Paul, MN.

28. Ndowora, T. C. R., Kinkel, L. L., Jones, R. K. and Anderson, N. A. 1996. Fatty acid analysis of pathogenic and suppressive strains of Streptomyces species isolated in Minnesota. Phytopathology 86:138-143.

29. Takeuchi, T., Sawada, H., Tanaka, F., an Matsuda, I. 1996. Phylogenetic analysis of Streptomyces spp. causing potato scab based on 16S rRNA sequences. Int. J. Syst. Bacteriol. 46:476-479.

30. Tashiro, N., Miyashita, K., and Suzui, T. 1990. Taxonomic studies on the Streptomyces species, isolated as causal organisms of potato common scab. Ann. Phytopathol. Soc. Jpn. 56:73-82

31. Williams, S. T., and Davies, F. L. 1965. Use of antibiotics for selective isolation and enumeration of actinomycetes in soil. J. Gen. Microbiol. 38:251-261. 